\title{
Pomen literarne vede pri izvajanju biblioterapije
}

Manca Marinčič

Univerza v Ljubljani, Filozofska fakulteta, Oddelek za primerjalno književnost in literarno teorijo, Aškerčeva 2, 1000 Ljubljana

https://orcid.org/0000-0001-8820-7206

manca.marincic@gmail.com

Danes se zavedamo pomena branja in njegovih učinkov na bralce, sajjih potrjujejo različne študije vpliva branja. Pomena branja ne raziskuje samo literarna veda, ampak je to raziskovalno področje zanimivo tudi za številne druge vede. Z biblioterapijo se raziskovalci ukvarjajo dobrih sto let, njene zasnove pa lahko opazimo že $v$ Bibliji in pri starogrških filozofih. Sodobne raziskave biblioterapije opravljajo predvsem raziskovalci s področij psihiatrije, psihologije, pedagogike in bibliotekarstva. Čeprav so knjige oziroma literatura osrednja komponenta procesa biblioterapije, je med avtorji člankov in samimi izvajalci biblioterapije le malo strokovnjakov z literarnovednega področja. Članek se posveča vlogi literarne vede pri izvajanju biblioterapije, zlasti vprašanju, kako lahko ta ključno prispeva h kvaliteti izbire besedila za izvedbo biblioterapije. Raziskuje, katere strategije preučevanja literarnih besedil lahko uporabimo pri iskanju besedila, da bo to ustrezno vplivalo na udeležence biblioterapije. Za to je pomemben psihonaratološki pristop $k$ izbiri besedila.

Ključne besede: literarna veda / biblioterapija / branje / naratologija / psihonaratologija / empatija

Besedilo, ki se ga uporabi za izvajanje biblioterapije, mora ustrezati določenim pogojem - pri bralcu mora dosegati željene terapevtske cilje. Ti so pogosto podrobni in točno določeni, kar zahteva podrobno in natančno izbiro ustreznega gradiva. Zaradi zapletenosti postopka si težko predstavljamo, da bi izbira besedila za biblioterapijo potekala brez predhodnega dobrega poznavanja literature, njenih zakonitosti in pomembnejših literarnih del. Kljub temu se pri raziskovanju biblioterapije redko srečamo z raziskovalnim delom strokovnjakov s področja literarne vede.

Članek ugotavlja, kakšna je vloga literarne vede pri procesu biblioterapije. Je strokovno poznavanje literarnovednega področja za ustrezno izbiro besedila pod tako zapletenimi pogoji nujno, ali je dovolj strokovno 
znanje s področja psihologije, psihiatrije ali pedagogike? Kako lahko k procesu pripomore sodelovanje strokovnjaka s področja literarne vede? Kako lahko k procesu prispeva psihonaratologija?

\section{Pomen branja}

$\mathrm{V}$ času razvoja digitalnih tehnologij se vedno bolj zavedamo pomena branja. Ko opažamo, da kultura branja knjig zamira, se posledično sprašujemo, kaj lahko s tem izgubimo. V času epidemije virusa Covid-19 sta se uporaba in razvoj digitalne tehnologije drastično povečala. $\mathrm{Na}$ vseh področjih vedno več uporabljamo digitalne vsebine. Celo v akademskem okolju, kjer smo bili v obstoj (tiskane) knjige najbolj prepričani, jo zamenjujejo različni spletni viri.

Kljub trenutni situaciji številne raziskave govorijo v korist tiskane knjige. Miha Kovač v svoji novi knjigi Berem, da se poberem: 10 razlogov za branje knjig $v$ digitalnih časih trdi, da so njegovi »trije veliki pregledi nekaj sto raziskav, opravljenih $\mathrm{v}$ zadnjih dvajsetih letih, $\mathrm{v}$ katerih so primerjali branje na papirju in zaslonu, [...] pokazali, da ljudje daljša in zahtevnejša besedila razumemo bolje, če jih beremo na papirju, kot če jih beremo na zaslonu« (50). Raziskovanje in poudarjanje pomena branja tiskanih knjig pa tudi branja na sploh (v digitalni in "analogni« obliki) je v trenutni situaciji izrednega pomena.

Branje ni prirojena veščina. Če želimo, da bo oseba brala, jo moramo tega namensko naučiti, pri čemer nam pomagata razvoj abecede in drugih pripomočkov. Bistvo učenja branja je v možganih oziroma njihovem spreminjanju. Premišljeno jih moramo oblikovati tako, da bodo lahko znake, ki jih bodo videli na papirju, preoblikovali v njim razumljiv jezik. Sodobne nevrološke raziskave so pokazale, da so možgani nepismenih ljudi v veliko pogledih drugačni od možganov pismenih. Branje vpliva na logično razmišljanje, na način, kako možgani procesirajo opažene znake in kako bralci sestavljajo spomine (Carr 55).

Vedno več vemo o vplivu branja na bralce. Tudi vedno bolje poznamo delovanje možganov, kar nam odkriva nove razsežnosti dojemanja umetnosti. Stvari, ki jih je literarna veda že prej poznala o dojemanju branja in načinu, kako določena besedila interpretiramo, lahko nevroznanost $s$ spremljanjem delovanja možganov zdaj še dodatno potrjuje (Armstrong 7).

V 21. stoletju stopnja bralne pismenosti zaskrbljujoče pada. Tudi zaradi novih spoznanj na tem področju vemo, da je bralna pismenost ključnega pomena za družbeni in gospodarski razvoj. Z nizko stopnjo 
pismenosti se srečujemo tudi v Sloveniji. Pri nas in po svetu se zato pospešeno išče načine, $s$ katerimi bi zvišali pismenost prebivalcev, $s$ čimer se že dolga leta ukvarja tudi Evropska unija. V šestdesetih letih je to nalogo prevzel Evropski svet. V dokumentu z naslovom »Key Competencies (Ključne zmožnosti) « iz leta 2002, ki ga je izdalo Evropsko informacijsko omrežje za izmenjavo podatkov o izobraževanju Eurydice, je bralna pismenost opredeljena kot "zmožnost razumeti, uporabljati in razmišljati o pisnih besedilih, da bi dosegli lastne cilje, razvili svoje znanje ter potenciale in učinkovito sodelovali v družbi« (Grosman 9).

Razsežnosti branja so velike in pomembne. Celotna družba sloni na bralni pismenosti in takoj, ko ta oslabi, čuti posledice. Če bomo na branje gledali s tega vidika in otroke že od malega učili, da branje ni obvezno, ampak nujno za doseganje osnovnih ciljev kvalitetnega življenja $v$ razviti družbi in gospodarstvu, potem bomo lahko upali na prihodnost, $\mathrm{v}$ kateri bo bralna pismenost samoumevna.

Za otroke vsakodnevno večerno branje predstavlja pomemben del dnevne rutine. Branje zgodbic (predvsem vedno istih zgodb) otroku omogoča doživljanje prijetnih čustev, varnosti in izpolnitev potrebe po skupni pozornosti. Poleg tega pa otrok, medtem ko posluša pripovedovano zgodbo, "uri spretnost usmerjene pozornosti« (Marjanovič Umek in Zupančič 27). Otroške knjige in slikanice so pomemben faktor tudi pri podpiranju govornega razvoja. Otroci, ki pri govornem razvoju niso dobili dovolj spodbud (v to štejemo branje staršev oz. drugih odraslih, otroške knjige, pomanjkanje spodbujanja k pripovedovanju in neodzivanje na govorne vzorce), glede na raziskave zaostajajo za tistimi, ki so bili ustreznih spodbud deležni, kar pozneje težko nadoknadijo (27-32).

Branje je pomemben sopotnik pri razvoju družbene in osebne identitete mladostnikov. Razvoj osebne identitete je ena izmed osrednjih nalog adolescence, pri čemer branje lahko igra ključno vlogo. Branje nam pomaga, da se lažje umestimo v svet, lažje vzpostavimo odnos do različnih družbenih struktur in omejitev. $S$ tem, ko bralci ustvarjajo odnose $s$ književnimi liki, raziskujejo različne osebnosti, ki jih lahko obkrožajo, se umeščajo v svet in spoznavajo sami sebe (Ross, McKechnie in Rothbauer 114-115).

Tudi v odrasli dobi ostane branje gradnik identitete, razvoja, formiranja stališč in čustvovanja:

Kot kulturni dosežek in veščina ima branje pomembno vlogo pri tem, kako ljudje vidijo sami sebe in kako nanje gledajo drugi. V sodobnem svetu je raven pismenosti posameznika ključna pri njegovem razumevanju sveta in njegovem samoizražanju. [...] Branje vpliva na posameznikovo vedênje in dejanja $v$ 
družbi, še posebno pa učinkuje na medčloveško komunikacijo in angažiranost v javnem življenju. (Furedi 183)

Branje dokazano vpliva na razvoj empatije pri bralcih. Še ne dolgo nazaj so obravnavanje empatije v literarni teoriji prezirali. Filmi in proza so narejeni tako, da pretentajo bralca ali gledalca $v$ sočustvovanje z liki (empatijo lahko občutimo tako pri negativnih kot tudi pri pozitivnih čustvih). Empatijo v prvi vrsti raziskujejo socialni psihologi in nevroznanstveniki. Povezava med psihologijo in literaturo pa je prispevek k obema vedama. Obe področji združuje psihonaratologija, ki raziskuje vplive naratoloških postopkov na psihologijo bralca (Keen 208-210).

Empatijo raziskujejo na več načinov: $z$ opazovanjem zaznavnih in nezaznavnih obraznih odzivov (nezaznavne merijo s pomočjo EMG elektromiografije), z merjenjem srčnega utripa in spremljanjem potenja rok oziroma prevodnosti kože, s sodelujočimi se pogovarjajo o njihovih odzivih na hipotetične situacije, stopnjo empatije pa na koncu merijo s posebnimi lestvicami empatije. Za raziskovanje je pomembno tudi fMRI slikanje. S spremljanjem odzivnosti možganov je Tania Singer s svojimi kolegi na primer ugotovila, zakaj se nam kljub temu, da ne doživimo dejanske senzacije, zdi, da čutimo bolečino drugega. Za razumevanje empatije je ključno tudi raziskovanje zrcalnih nevronov, ki pojasnjujejo posnemanje kot eno od osnovnih sestavin človekovega vedenja. Raziskuje se tudi ali lahko z umetnostjo, literaturo in učenjem spreminjamo njihovo aktivnost. Slike možganov pa so zdaj tudi dokaz za prejšnje raziskave (Keen 209-211).

Teorija narativne empatije raziskuje učinke narativnih postopkov na empatijo. Izkušnje bralcev se seveda razlikujejo. Raziskovanje odkriva zanimive povezave med besedilom in njegovim vplivom na bralca. V ugotovitvah iz raziskav teh povezav med drugim zasledimo, da empatijo do nekega literarnega lika lahko bralec razvije tudi v primeru, ko je karakterizacija tega lika manj razvita in bralec nima veliko podatkov o njegovi/njeni identiteti; empatijo do literarnega lika pogosteje razvijemo v primeru negativnih čustev, pomembno pa je tudi dejstvo, da empatija sploh ni nujna posledica branja fikcije, ki vzbuja čustva, saj različni bralci na isto besedilo različno reagirajo; bralci se že v osnovi razlikujejo po svojih dispozicijah za občutenje empatije, nekateri jo občutijo pogosteje in bolj izrazito kot drugi. Tudi avtor ne more nadzirati odziva svojih bralcev. V nekaterih bralcih empatijo vzbudijo konvencije in žanri, pri drugih pa se to prav nasprotno zgodi z branjem presunljivih in neverjetnih upodobitev. Narativni postopki, ki vzpodbujajo identifikacijo z likom in posledično tudi empatijo, so na 
primer opis, poimenovanje, tipizacija, posredno nakazovanje določenih značilnosti, upodobljena dejanja idr. (Keen 214-216).

\section{Psihonaratološki pristop}

Psihonaratologija empirično preučuje mentalne procese in odzive na naracijo ter besedilne strukture in značilnosti. Ukvarja se s psihološkim odzivom na različne narativne oblike. Pri raziskovanju je pomembno, da bralce med branjem opazujemo sistematično, kar je edini način, da odgovorimo na empirična vprašanja. Kako bo bralec obravnaval neko besedilo, je odvisno od vsakega bralca posebej, od okolja, v katerem bere, in narave besedila. Pri preučevanju bralčevega odziva nas zato zanima razmerje med temi tremi pogoji/spremenljivkami. Naloga je sicer zahtevna, a se jo z "vzpostavljenimi metodologijami« (Bortolussi in Dixon 35) in »eksperimentalnimi paradigmami« (35) da doseči (24-35).

Razlikovati moramo med bralčevimi interpretacijami in dejanskimi značilnostmi besedila. Če razlikujemo med tema dvema pojmoma, lahko vpeljemo uporabo orodij, ki nam bodo pomagala razumeti različna stališča narativne obdelave. $\mathrm{Na}$ tak način lahko konstruiramo odgovore na splošna vprašanja, ki veljajo za večino z izjemami. Pripovedovalec je $\mathrm{v}$ bistvu obenem $\mathrm{v}$ besedilu in $\mathrm{v}$ bralcu. Najtežja naloga je ravno ta, da združimo dve nasprotni si prepričanji o bralcu: da je odziv na prebrano od bralca do bralca drugačen in zato ne more biti homogen in da bralčev odziv vseeno ni čisto poljuben in se ga zato da znanstveno raziskovati in opisovati (Bortolussi in Dixon 37-43).

Dixon, Bortolussi, Twilley in Leung so (v članku »A Literary processing and interpretation: Towards empirical foundations", leta 1993 v reviji Poetics) konstruirali tudi pojem "statističnega bralca«. Kot nam pove že samo ime, pojem sloni na statistiki in verjetnosti. Uporaba "statističnega bralca" je razdeljena na dva dela. Najprej poskušamo sestaviti čim bolj osnoven opis dveh ključnih konceptov: porazdelitve $\mathrm{v}$ statistični populaciji in porazdelitve meritev, potem pa ta formalni opis uporabimo kot osnovo za ponazoritev razmerij in spremenljivk. Ko ideje nedvoumno opredelimo, kar je del vsake standardne analize podatkov, omogočimo razvoj metodološkega okvira. Kljub temu avtorji poudarjajo, da analize vpliva branja ne želijo omejiti samo na "opisovanje specifičnih in tipičnih interpretacij besedila«. Nalogo psihonarotologije prav nasprotno vidijo v obravnavanju različnih bralcev kot celote in njihovega odziva na besedilo (Bortolussi in Dixon 43-44). Psihonaratološki pristop $\mathrm{k}$ preučevanju (literarnih) besedil lahko $\mathrm{s}$ 
svojimi postopki pomembno prispeva $\mathrm{k}$ ustrezni izbiri besedila za izvajanje biblioterapije.

\section{Kaj je biblioterapija?}

Zametke biblioterapije zasledimo že v Bibliji in pri starogrških filozofih. V Bibliji sicer nikoli ni izrecno omenjen izraz "terapija", a se ta $\mathrm{v}$ judovsko-krščanski tradiciji z njim neposredno povezuje. $S$ terapevtskega vidika so pomembni predvsem Jobova knjiga, Nova zaveza in poročila o Jezusu (Reščič Rihar in Urbanija 21). Platon se je zavedal močnega vpliva literature na bralca. $\mathrm{V}$ deseti knjigi Države na primer razmišlja o škodljivih učinkih pesništva, tragedije (606a) in komedije (606c). Ko govorimo o odnosu starogrških filozofov do vpliva literature, ne moremo mimo Aristotela, ki je vpeljal pojem katarze oziroma očiščenja. Omenja jo že v Politiki (1341b), v kateri napoveduje njeno podrobnejšo obravnavo v Poetiki. Tam jo v slavni definiciji tragedije sicer omeni (1449b), ampak zgolj na kratko. Predvideva se, da jo je podrobneje pojasnil v izgubljeni drugi knjigi Poetike. Ker podrobnejša razlaga umanjka, so katarzo pokušali pojasniti številni raziskovalci, ki so jo večinoma povezovali z zdravljenjem in terapijo (Gantar 38-47).

$\mathrm{V}$ procesu biblioterapije uporabimo branje ali avdiovizualno gradivo (npr. filme) z namenom, da bi sodelujoči s pomočjo izvajanja biblioterapije izboljšali svoje mentalno zdravje, da bi jim pomagali do osebnostne rasti ali pa zgolj do razmisleka o samem sebi. Gre za klinično orodje, ki ga uporabljajo strokovnjaki za duševno zdravje (tudi drugi usposobljeni biblioterapevti, odvisno od primera). Poleg branja postopek vključuje tudi aktivno vključevanje bralcev, dodatno umetnostno ustvarjanje (npr. pisanje) in pogovor (McCulliss 23).

Izraz biblioterapija je prvi uporabil Samuel Crothers v članku leta 1916. Poleg tega termina se danes pojavljajo tudi nekateri drugi, na primer vodeno branje, literarna terapija in bibliosvetovanje. Pomembno je razlikovanje med različnimi vrstami biblioterapije, na primer med klinično biblioterapijo, ki jo izvajajo za to usposobljeni psihologi, in razvojno biblioterapijo, ki jo lahko z zdravimi udeleženci izvajajo tudi drugi, npr. učitelji (Pehrsson in McMillen 48).

Reščič Riharjeva in Urbanija razdelita biblioterapijo na klinično, razvojno in institucionalno biblioterapijo. Institucionalna biblioterapija se zdaj ne uporablja več tako pogosto. Gre za odnos med terapevtom in pacientom $v$ okolju bolnišnice oziroma institucije. $\mathrm{V}$ tem primeru se biblioterapija večinoma izvaja kot podporna dejavnost med preživlja- 
njem prostega časa. Zanjo se uporabljajo predvsem besedila o duševnem zdravju. Tudi klinična biblioterapija se večinoma izvaja $\mathrm{v}$ institucionalnem okolju ali v drugih oblikah skupnosti. Izvajata jo zdravnik ali knjižničar, v večini primerov pa kar oba skupaj, tako da si lahko pri delu pomagata in sodelujeta. Skupino vodi knjižničar, ki tudi izbere ustrezno gradivo, večinoma leposlovje, pri tem pa mu s svetovanjem pomaga zdravnik. Cilj take biblioterapije je sprememba pacientovega obnašanja. Tako pri institucionalni kot tudi pri klinični biblioterapiji so zelo pomembne knjižnice $\mathrm{v}$ ustanovah, $\mathrm{v}$ katerih se biblioterapija izvaja. Poleg tega je pomembno tudi sodelovanje knjižničarjev, zdravnikov in zdravstvenih delavcev (Reščič Rihar in Urbanija 16).

Razvojna biblioterapija se uporablja pri zdravih ljudeh za ohranjanje »duševnega zdravja, normalni osebnostni in telesni razvoj in za samouresničevanje» (Reščič Rihar in Urbanija 17). Njena posebnost je v tem, da jo lahko izvajajo ljudje, ki opravljajo različne socialne poklice, učitelji in knjižničarji. Razvojna biblioterapija se lahko izvaja z ljudmi vseh starosti, predvsem pa takrat, ko se ti spopadajo z določenimi stiskami in potrebujejo pomoč (npr. smrt in ločitev). Izvaja se lahko v šoli, knjižnici ali različnih društvih. Vse tri naštete vrste biblioterapije slonijo na "pogovor[u] o prebranih knjigah in knjižnih gradivih", vsaka pa zahteva različno stopnjo usposobljenosti biblioterapevta (Reščič Rihar in Urbanija 17).

Proces biblioterapije lahko razdelimo na posamezne univerzalne dele. Kljub temu pa se je potrebno pred izvajanjem pozorno posvetiti duševnemu stanju udeležencev, da jim lahko zagotovimo ustrezno obravnavo. Zgodbo moramo predstaviti na tak način, da se bodo udeleženci vanjo aktivno vključili. Terapevtov cilj je, da glede na udeleženčeve osebne težave izbere ustrezen način za vzbujanje določenih čustev, $s$ katerimi ga bo pripeljal do razumevanja in rasti (Heath idr. 566-567).

Proces razdelimo na pet delov: "vpletenost", »identifikacija», "katarza", "uvid" in "posplošitev" (Heath idr. 567). Cilj je, da se udeleženci ob poslušanju začnejo zanimati za zgodbo, se vanjo vpletejo in začnejo sodelovati. Ob naslednjem koraku se začenjajo z liki identificirati (običajno najbolje s tistimi, ki se soočajo s podobnimi težavami in so podobne starosti). Identifikacija jim omogoča, da se tako močno vpletejo v zgodbo in z likom poglobljeno čustvujejo, da z njim globoko doživijo zaplet zgodbe in ob njenem razpletu doživijo čustveno očiščenje oziroma katarzo, ki je tretji del procesa. V četrtem delu (uvidu) udeleženci dogodke iz zgodbe začnejo primerjati s svojim življenjem. Če je proces učinkovit, začnejo iskati rešitve za podobne težave, $s$ katerimi se srečujejo sami in dobijo upanje, da jih bodo razrešili. V fazi posplošitve 
udeleženci razmišljanje iz sebe usmerijo navzven in ga razširijo. $S$ tem ugotovijo, da so težave, s katerimi se srečujejo, splošne. Ko odkrijejo, da se tudi drugi srečujejo s podobno bolečino, izgubijo občutek izoliranosti in osamljenosti ter občutijo neke vrste podporo (567).

Ko raziskujemo biblioterapijo, pogosto naletimo na polemike glede ustreznosti biblioterapevtov. Kdo je usposobljen in primeren za izvajanje biblioterapije? Rekli bi lahko, da je to v veliki meri odvisno od vsakega posameznega primera. Pred izvajanjem biblioterapije bi se morali vprašati, katere so potrebe udeležencev in kakšnega biblioterapevta te zahtevajo. Večina literature zagovarja interdisciplinarnost biblioterapevtov, ki bi imeli znanje iz različnih področij, ki so za biblioterapijo vzajemno koristna.

Vlasta Zabukovec zagovarja drugačno stališče. Njena osnovna teza je, da je biblioterapija ustrezno poimenovanje zgolj za biblioterapevtski proces $\mathrm{v}$ kliničnih institucijah oz. kliničnem okolju. Vseh ostalih procesov, ki jih izvajamo $\mathrm{v}$ šolah in knjižnicah, zato ne moremo imeti za biblioterapevtske. Posledično tudi izvajalcev takšnih procesov ne moremo imenovati biblioterapevti. Po njenem mnenju je rešitev $\mathrm{v}$ "procesu svetovanja«. $\mathrm{Z}$ njim bi poimenovali proces preventivne in razvojne biblioterapije. Preimenovanje procesa v »bibliosvetovanje« utemeljuje tudi z dejstvom, da »knjižničarji [...] niso usposobljeni za delo z duševno bolnimi osebami, ampak vodijo pogovore o prebranem z duševno zdravimi osebami" (Zabukovec 25-26).

$\mathrm{Z}$ uporabo drugega izraza težave ne rešimo, ampak jo samo preusmerimo. Če za isti proces zgolj uporabimo drug izraz, ne samo spremenimo situacije, ampak ji samo nadenemo drugo ime. Prav tako debato bi lahko začeli o ustreznosti psihologov, psihiatrov in drugih zdravstvenih delavcev za delo z literaturo. So ti ustrezno usposobljeni za preučevanje in ocenjevanje literature? Je klinično okolje primerno za uporabo literature? Rešitve ne bomo našli s tako enostranskimi in enoznačnimi trditvami. Ključ je v povezovanju in interdisciplinarnosti.

Biblioterapijo izvajajo knjižničarji, zdravniki, psihoterapevti, psihologi, socialni delavci in pedagogi, vsi pa menijo, da je uporaba literature $v$ terapevtske namene njihova domena. Knjižničarji so prepričani, da je biblioterapevt lahko knjižničar s posebnimi znanji s področja psihologije, lahko pa tudi psiho$\log$ z znanjem knjižničarstva. Obe mnenji sta pravilni, če ima biblioterapevt tudi potrebne osebnostne lastnosti in znanje o literaturi. Najuspešnejši izvajalci biblioterapije so bili timi, sestavljeni iz psihologa, psihiatra, knjižničarja, poklicnega terapevta, socialnega delavca in pedagoga, kar spet dokazuje, da biblioterapija zahteva interdisciplinaren pristop in da so uspešni biblioterapevti tisti, ki združujejo znanja iz naštetih področij. (Reščič Rihar in Urbanija 17) 
$\mathrm{Na}$ tem mestu želim poudariti, da med ustrezne izvajalce biblioterapije štejem tudi komparativistke in komparativiste oziroma strokovnjake $s$ področja literarne vede, ki se jih v literaturi o biblioterapiji skorajda ne omenja. To področje je nekako pripadlo bibliotekarski stroki, a so za opravljanje podobnih nalog v procesu biblioterapije usposobljeni tudi drugi strokovnjaki s področja literarne vede.

\section{Izbira besedila}

Pri različnih avtorjih zasledimo različne razdelitve biblioterapevtskega procesa in tudi različna poimenovanja za posamezne faze. Vsem pa je skupno to, da najprej izberejo ustrezno besedilo. Pri izbiri besedila moramo biti pozorni na značilnosti sodelujočih (npr. njihovo starost in izobrazbo), na kulturno okolje in veliko drugih faktorjev. Sheryl O'Sullivan je $\mathrm{v}$ ta namen literaturo razdelil na štiri dele: »knjige, ki vključujejo moralne dileme«, »knjige s poglobljenim (psihološkim) pristopom «, »knjige, ki opisujejo resnične značaje oseb in so povezane $\mathrm{z}$ želenimi« in "knjige z različnimi kulturnimi ozadji in zastopanostjo obeh spolov« (Zabukovec 24-25).

Biblioterapevt mora pred izbiro literature dobro poznati vsakega posameznika iz skupine. Tako se lahko vsakemu posebej čim bolj prilagodi z izbranim gradivom. Nekateri avtorji svetujejo poseben izbor za vsako specifično psihofizično stanje udeleženca. Za različne diagnoze sodelujočih naj bi bila po mnenju nekaterih primerna različna literatura (npr. leposlovje za psihične bolnike ali pa strokovna literatura za zasvojence). Tem ugotovitvam ne moremo slepo slediti, saj so poleg njih pomembni tudi bralni interesi sodelujočih (Reščič Rihar in Urbanija 39).

Čez leta so za uporabo pri biblioterapiji nastali različni sistemi oziroma modeli, s pomočjo katerih lahko izberemo ustrezno literaturo. Objavljeni so bili tudi celi seznami knjig, ki so bile primerne za izvajanje biblioterapije. Avtorji takih sistemov in seznamov so poskušali ugotoviti osnovne kriterije, ki jih morajo izpolnjevati izbrane knjige. $\mathrm{V}$ povezavi z izbiro literature so se avtorji ukvarjali tudi s posameznimi literarnimi zvrstmi: "Leposlovje je najbolj uporabno knjižno gradivo v biblioterapiji. Najbolj primerni so romani. Sledijo jim črtice, biografije, pravljice, znanstvena fantastika ..." (Reščič Rihar in Urbanija 41)

Pri izbiri literature za biblioterapijo je ključno dobro poznavanje besedila, ki je kompleksna enota. Literarna veda lahko s svojim razvejenim teoretičnim aparatom igra osrednjo vlogo pri izvajanju procesa 
biblioterapije. V sodelovanju z ostalimi strokovnjaki lahko prav pri fazi izbiranja besedila ponudi vrsto različnih metodoloških pristopov, ki ostalim vedam manjkajo, so za izvedbo kvalitetnega procesa nujni. Posamezne značilnosti in deli besedila lahko zelo specifično vplivajo na bralca, zato jih je nujno raziskati in upoštevati pri izbiri besedila za izvajanje biblioterapije.

\section{Prispevek literarne vede}

Klemen Lah v svojem članku »(Biblio)terapevtski procesi med poukom književnosti« na podlagi svoje izkušnje študija opozarja na izrinjenost doživljanja branja iz študijskega procesa pri študiju književnosti in odpor do biblioterapije $\mathrm{v}$ literarni vedi.

Biblioterapija med študijem književnosti ni razumljena kot nujen, še manj samoumeven del študijskega procesa. Del razlogov je gotovo iskati v odporu do njenih metod, načel in orodij, ki postavljajo pod vprašaj samoumevnost strogo kognitivnega raziskovalnega aparata literarne vede. Da je temu tako, mi je dokazovalo kar nekaj izkušenj. Že na začetku študija slovenske književnosti nas je takratni predavatelj opozoril, da naj med študijem književnosti ne pričakujemo, da 'bomo brali knjige in jokali drug drugemu na ramenih'. Njegovo karikirano in ironično obarvano izjavo sem razumel kot sporočilo, naj do književnih del pristopamo racionalno, kognitivno in z znanstveno preverjenim metodološkim aparatom literarne vede. (Lah 45)

Odpor do biblioterapije ni potreben. Literarna veda je zmožna literarni odziv obravnavati racionalno, kognitivno in znanstveno preverjeno, obenem pa ohraniti subjektivno, ki je neizogiben del bralčeve recepcije literarnega dela. Za biblioterapijo je pomembna zato, ker ima teoretski aparat, ki ji omogoča, da vpliv literature na bralca raziskuje empirično, obenem pa lahko pri raziskovanju upošteva, da je vsako razumevanje posameznega bralca specifično.

V drugi polovici šestdesetih let se je zgodil prehod »v tretjo metodološko paradigmo literarne vede« (Virk, Moderne 215). K temu prehodu je prispeval tudi Gadamer, ki je v svoji filozofski hermenevtiki poudarjal, da se interpretovih predsodkov ne moremo znebiti in da bo bralčeva recepcija v vsakem primeru zgodovinska, ukvarjal se je tudi z izvirnim horizontom dela (horizont v katerem delo nastane), horizontom sedanjosti (v katerem se delo razumeva) in zlitjem oziroma stopitvijo horizontov. V njegovem raziskovanju je že razviden pomemben premik, ki se je zgodil v literarni vedi $v$ šestdesetih letih, in sicer premik usmeritve 
pozornosti od avtorja in dela $\mathrm{k}$ bralcu. $\mathrm{Z}$ vprašanjem bralčeve recepcije sta se ukvarjali predvsem recepcijska estetika in ameriška teorija bralčevega odziva (reader-response criticism) (215-217). Glavna predstavnika recepcijske estetike (in t. i. konstanške šole) sta Hans Robert Jauß in Wolfgang Iser, ki sta oblikovala dve temeljni raziskovalni usmeritvi recepcijske metode: estetiko recepcije (Jauß) in estetiko učinkovanja (Iser) (217), glavni predstavniki teorije bralčevega odziva pa so Stanley Fish, David Bleich, Jonathan Culler, Norman Holland in v nekaterih virih tudi Wolfgang Iser (Pezdirc Bartol 41). Pozneje so se z razlaganjem vpliva literature na bralca ukvarjali še raziskovalci razmerja med literaturo in etiko, psihonaratologija, narativna empatija, sodobne nevroznanstvene raziskave branja (nevrobiologija branja) idr.

Doživljanje literarnega dela lahko raziskujemo ravno $\mathrm{z}$ uporabo metodološkega aparata literarne vede. Biblioterapija, doživljanje branja in občutenje bralca ne predstavljajo nevarnosti za strokovnost in znanstvenost literarne vede. Ravno pri obravnavi teh področij znova dokažemo univerzalnost njenega metodološkega aparata, ki je aplikabilen tudi na področja, ki so se do zdaj zdela preveč subjektivna in zato neprimerna za znanstveno obravnavo:

Zdaj nam že mora biti jasno, da so pripombe o bralcih ali učinkih branja le redko samo nevtralna opažanja. Ne glede na to, ali hvalijo ali kritizirajo bralce, vedno temeljijo na subjektivni izkušnji komentatorja in na njegovih prepričanjih o vrednosti pismenosti. Četudi so ubesedene v tehničnem ali znanstvenem žargonu, so izjave o bralcih in branju vedno preskriptivne. Določajo jih vsakokratne okoliščine, kot so vrednote, estetski okus, družbena ureditev, izobrazba in pogled na človekove zmožnosti. (Furedi 178)

Seveda se bo zaradi narave teme, kot je recepcija branja, pojavljalo več subjektivnih opažanj, kot bi se jih morda pri raziskovanju neke druge teme. Tudi odzivi bralcev se med seboj vedno razlikujejo. Kljub vsemu se odziv na branje da raziskovati na empiričen in znanstven način, samo uporabiti moramo za to prilagojena orodja in postopke. Bortolussi in Dixon na primer priporočata, da pri raziskovanju različne bralce obravnavamo kot celoto ali pa si pomagamo s »statističnim bralcem" (43-44).

Raziskave vpliva literature na bralca in zavedanje o terapevtskih razsežnostih literature niso nič novega. $\mathrm{V}$ zadnjih stoletjih se raziskovalci $s$ tem poglobljeno ukvarjajo. Odraz raziskav povezave med literaturo in terapijo je tudi terapija s poezijo. Nicholas Mazza je napisal delo Terapija s poezijo: teorija in praksa, ki je temeljnega pomena za to področje. Mazza v knjigi omeni tudi katarzo in jo označi za pomemben del sodobne psihoterapije, psihodrame in skupinske psihoterapije. 
Začetki uporabe poezije v sodobnem času sežejo v začetek 19. stoletja. $\mathrm{Na}$ teoretično osnovo terapije s poezijo so vplivali predvsem Freudova psihoanaliza in Jungova analitična psihologija, Adlerjeva psihologija, Gestalt terapija in psihodramska teorija. Mazza v knjigi konstruira tudi praktični model izvajanja terapije s poezijo. Med biblioterapijo in terapijo s poezijo lahko potegnemo številne vzporednice (Mazza 5-17). Ker gre pri terapiji s poezijo prav tako za povezavo med literaturo in terapijo, lahko raziskave $s$ tega področja uporabimo kot zgled za povezovanje biblioterapije s področjem literarne vede.

Literarna veda lahko poleg poznavanja besedil in njihovih značilnosti (na primer tipov pripovedovalca, literarnih zvrsti, žanrov, motivov in tem, stila, ritma idr.) $\mathrm{k}$ biblioterapiji prispeva predvsem $\mathrm{z}$ raziskovanjem literarnega odziva, naratologijo, teorijo narativne empatije in psihonaratologijo. $Z$ vsemi naštetimi načini raziskovanja literature lahko literarna veda pripomore predvsem k ustrezni izbiri besedila za biblioterapijo, ki je za biblioterapevtski proces osrednjega pomena. Te raziskave pomagajo pri razumevanju vpliva literarnega besedila na bralca, ki ga moramo, ko izbiramo besedilo za biblioterapijo, za katerega želimo, da ima na določenega sodelujočega točno določen vpliv, tudi praktično uporabiti.

Ugotovitve recepcijske estetike in teorije bralčevega odziva (predvsem Jaußova estetika recepcije in Iserjeva estetika učinkovanja) lahko služijo kot teoretična podlaga pri iskanju ustreznega besedila. To so na primer Jaußova razlaga pojmov kot so horizont pričakovanja, estetska distanca, estetsko izkustvo in njegova ponazoritev postopka iskanja vprašanj, na katera odgovori literarno delo s pomočjo rekonstrukcije primarnega horizonta pričakovanja (Virk, Moderne 218-220). Pri razumevanju poteka identifikacije bralca z literarnim likom, ki je temeljni del biblioterapevtskega procesa, si lahko pomagamo z njegovim opisom petih ravni estetskega izkustva, na katerih se izvrši identifikacija z junakom, ki ga najdemo v delu Estetsko izkustvo in literarna hermenevtika (Jauß 147). V pomoč nam je lahko tudi Iserjev opis lastnosti, po katerih se literarno besedilo razlikuje od neliterarnega besedila ter njegova analiza pogojev, pod katerimi literarno besedilo učinkuje na bralca in kako to učinkovanje spodbuja njegovo dejavnost. Prav tako so za nas pomembne Iserjeve ugotovitve, povezane $s$ praznimi mesti oziroma vrzelmi v literarnem delu, ${ }^{1} \mathrm{ki}$ jih bralec med branjem zapolnjuje, kar mu omogoča, da aktivno sodeluje pri ustvarjanju namena nekega besedila in delo razume drugače kot drugi bralci istega besedila (Dolinar

\footnotetext{
${ }^{1} \mathrm{Na}$ ta del njegovega raziskovanja je imel velik vpliv Roman Ingarden.
} 
365-366). Pomembno je tudi njegovo razumevanje besedila kot polisemantične enote in njegove analize funkcij fiktivnega, predvsem njegova razlaga vzrokov in razlogov, ki v bralcu vzbudijo duševne procese in mu omogočijo, da lahko ob branju doživi pravo izkušnjo, kar ima tudi neposreden vpliv na njegovo obnašanje v družbi (368-370).

Tudi psihonaratologija, ki združuje teoretična aparata psihologije in naratologije, ki skupaj tvorita specifičen pristop k preučevanju vpliva branja na bralca, nam služi kot teoretična opora pri izbiri besedila, ki ga uporabimo za izvajanje biblioterapevtskega procesa. Pri tem so nam $\mathrm{v}$ pomoč rezultati njenega preučevanja vpliva naracije, karakterizacije, fokalizacije in percepcije, dogajanja in zgodbe ter drugih značilnosti določenega besedila na psihologijo bralca. Bortolussi in Dixon sta z empirično raziskavo na primer ugotovila, da si bralec pripovedovalčevo izkušnjo razlaga na podlagi svojega znanja in izkušenj. S tem pripovedovalčeve izkušnje približa svojim izkušnjam in se z njim identificira, kar pripelje do transparentnosti (transparency), do katere pride, ko se bralcu zdi, da v celoti razume pripovedovalčeve misli, obnašanje in čustva (Bortolussi in Dixon 60-96).

$\mathrm{V}$ tem kontekstu velja omeniti tudi razmerje literature in etike, $s$ katerim se je v slovenskem prostoru $\mathrm{v}$ zadnjih letih intenzivno ukvarjal Tomo Virk. ${ }^{2}$ Razmerje literature in etike se ukvarja s podobnimi vprašanji kot recepcijska estetika, a se jih loteva drugače, in sicer z etičnega vidika. Ukvarja se tudi z vprašanjem empatije, ki jo v bralcih vzbudijo literarna dela. Virk v knjigi Literatura in etika med drugim obravnava empatijo, ki jo roman Bralec Bernharda Schlinka vzbudi pri svojih bralcih, ki ob branju tega romana empatijo občutijo do surove zločinke. Posveča se empatiji in tekstni strategiji, ki jo avtor uporabi, da bralca privede do tega, da empatijo občuti, a ga to vprašanje zanima predvsem $\mathrm{z}$ etičnega vidika. $\mathrm{V}$ tem primeru torej ugotavlja, če z avtorjevo zvijačo dosežena empatija do nekoga, ki je zagrešil nekaj neetičnega, vpliva na etični potencial literature (147-162).

$\mathrm{Za}$ raziskovanje vpliva branja na bralca je koristno tudi povezovanje literature in nevroznanosti. Nevroznanost lahko k raziskovanju literarne vede doprinese predvsem z merjenjem možganske aktivnosti. Metode, $s$ katerimi to izvajamo so: PET, MRI, fMRI, CT, EEG idr. Te so pri aplikaciji na raziskovalno področje literarne vede različno učinkovite. fMRI metoda je na primer predraga, metodi MRI in CT pa nista dovolj natančni oziroma z njima ne moremo raziskovati odziva

${ }^{2} \mathrm{~V}$ zadnjih letih sta izšli dve njegovi monografiji, ki se ukvarjata z razmerjem literature in etike: Etični obrat v literarni vedi (2018) in Literatura in etika (2021). 
možganov na nek dražljaj. Če odmislimo stroške fMRI metode, sta za uporabo pri raziskovanju literarne recepcije zares uporabni samo metodi fMRI in EEG (Žunkovič 218-220).

\begin{abstract}
Nevrološke karakteristike delovanja možganov nasploh so torej lahko koristne za boljše razumevanje kognitivnih procesov, ki so vključeni v recepcijo literarni tekstov, a trenutno še ni mogoče specificirati razlik med branjem literarnih in neliterarnih tekstov, različnih vrst literarnih tekstov in vseh razlik med branjem in poslušanjem literature. Toda vse to so področja, ki so danes dostopna raziskovanju, tako da je mogoče pričakovati, da bomo v neposredni prihodnosti na vseh teh področjih pridobili pomembne podatke, ki jih bo potrebno reflektirati skozi prizmo literarne vede. (Žunkovič 223-224)
\end{abstract}

Poleg sodelovanja pri izbiri literature za biblioterapijo lahko strokovnjaki s področja literarne vede pri biblioterapiji sodelujejo tudi kot njeni izvajalci. Za to se morajo o njej tudi dodatno izobraziti. Najboljše je, če se izbira biblioterapevta prilagodi vsakemu posameznemu primeru. Predvsem se mi zdi smiselno, da se v pogovoru s psihologom, psihiatrom ali psihoterapevtom ugotovi, če lahko komparativist, knjižničar ali drug strokovnjak $s$ področja literarne vede biblioterapijo $\mathrm{v}$ konkretnem primeru izvaja samostojno ali je za to potrebno sodelovanje terapevta. $V$ vsakem primeru pa je najbolj kvaliteten interdisciplinarni pristop.

\title{
Sklep
}

Čas, v katerem smo se znašli, nas je med drugim opomnil tudi na krhkost in pomembnost duševnega zdravja. Sanacija posledic epidemije se ne bo opravljala samo na gospodarskem področju. Pomembno bo okrevanje zdravstva kot sistema in zdravja vsakega posameznika - da, tudi tistih, ki ne bodo zboleli za virusom Covid-19. Epidemija bo pustila posledice na duševnem zdravju prebivalstva. Pri večini, ki bo najverjetneje utrpela blažje posledice, bo biblioterapija, kot oblika terapije, ki se jo lahko uporablja tudi pri duševno zdravem prebivalstvu za ohranjanje duševnega zdravja in za spopadanje z določenimi stiskami, uporabna oblika spopadanja z duševnimi posledicami epidemije.

Poleg številnih področij, na katerih je literarna veda zaradi razvejenega območja svojega raziskovanja koristna, je lahko uporabna tudi pri odkrivanju terapevtskih razsežnosti literature oziroma pri procesu biblioterapije. Trend zavedanja pomembnosti duševnega zdravja ni nov. Začel se je že veliko let pred epidemijo, o čemer med ostalim priča 
tudi vedno večja prodaja knjig za samopomoč. Terapevtskih učinkov literature in konkretno biblioterapije ne bodo potrebovali samo tisti, ki se bodo spopadali z duševnimi posledicami epidemije. Potrebovali jo bodo otroci in mladostniki, ki se spopadajo z vedno večjimi obremenitvami hitro razvijajočega se sodobnega sveta in odrasli, ki te otroke vzgajajo, poleg tega pa so sami izpostavljeni zahtevam, obveznostim in skrbem, ki jih ta svet prinaša. Nenazadnje jo bodo potrebovali starejši (skupina, ki jo vse prepogosto zanemarjamo, na kar nas je na krut način opomnila tudi epidemija), ki se bodo s pomočjo biblioterapije lažje spopadali s težavami in stiskami, ki jih prinaša starost.

Pričujoči članek ugotavlja, da je lahko literarna veda ključnega pomena za kvalitetno izveden proces biblioterapije. Psihologi, psihiatri in pedagogi nimajo določenih znanj, ki jih $\mathrm{v}$ tim prinaša strokovnjak $\mathrm{s}$ področja literarne vede. Duševno zdravje posameznika je neposredno povezano s splošnim stanjem družbe. K izboljšanju enega in drugega lahko prispeva tudi biblioterapija. $S$ kognitivnim, racionalnim in znanstvenim raziskovanjem, $\mathrm{v}$ katerega je vključeno subjektivno kot neizogiben del procesa branja, lahko literarna veda prispeva ne samo $\mathrm{k}$ izvajanju biblioterapije, ampak tudi $\mathrm{k}$ dobrobiti širše skupnosti. To možnost pa bi bilo neodgovorno še naprej zanemarjati.

\section{LITERATURA}

Armstrong, Paul B. Kako se literatura igra z možgani?: nevroznanost umetnosti in branja. Prev. Igor Žunkovič. Ljubljana: Znanstvena založba Filozofske fakultete, 2015.

Bortolussi, Marisa, in Peter Dixon. Psychonarratology: Foundations for the Empirical Study of Literary Response. Cambridge, New York, NY: Cambridge University Press, 2003.

Carr, Nicholas G. Plitvine: kako internet spreminja naš način razmišljanja, branja in pomnjenja. Prev. Tanja Ahlin. Ljubljana: Cankarjeva založba, 2011.

Dolinar, Darko. „Od recepcijske teorije k literarni antropologiji«. Spremna beseda. Bralno dejanje: teorija estetskega učinka. Avtor Wolfgang Iser. Ljubljana: Studia humanitatis, 2001. 359-378.

Furedi, Frank. Moč branja: od Sokrata do Twitterja. Prev. Sandi Kodrič. Ljubljana: UMco, 2017.

Gantar, Kajetan. »Uvodna razlaga«. Poetika. Aristoteles. Ljubljana: Študentska založba, 2012. 9-68.

Grosman, Meta. Razsežnosti branja: za boljšo bralno pismenost. Ljubljana: Karantanija, 2006.

Heath, Melissa Allen, idr. »Bibliotherapy: A resource to facilitate emotional healing and growth". School Psychology International 26.5 (2005): 563-580.

Jauss, Hans Robert. Estetsko izkustvo in literarna hermenevtika. Prev. Tomo Virk. Ljubljana: LUD Literatura, 1998.

Keen, Suzanne. »A Theory of Narrative Empathy«. Narrative 14.3 (2006): 207-236. 
Kovač, Miha. Berem, da se poberem: 10 razlogov za branje knjig $v$ digitalnih časih. Ljubljana: Mladinska knjiga, 2020.

Lah, Klemen. »(Biblio)terapevtski procesi med poukom književnosti«. Čudežnost besed: bibliopreventiva. Zbornik ob mednarodni konferenci o biblioterapiji/bibliopreventivi. Ur. Sabina Burkeljca. Domžale: občina Domžale, 2010. 43-51.

Marjanovič Umek, Ljubica, in Maja Zupančič. „Vloga branja in pripovedovanja v otrokovem razvoju". Beremo skupaj: priročnik za spodbujanje branja. Ur. Marina Blatnik Mohar. Ljubljana: Mladinska knjiga, 2003. 22-33.

Mazza, Nicholas. Poetry Therapy: Theory and Practice. Hove; New York, NY: Brunner; Routledge, 2003.

McCulliss, Debbie. "Bibliotherapy: Historical and research perspectives«. Journal of Poetry Therapy: The Interdisciplinary Journal of Practice, Theory, Research and Education 25.1 (2012): 23-38.

Pehrsson, D., in P. S. McMillen. »A Bibliotherapy evaluation tool: Grounding counselors in the therapeutic use of literature». The Arts in Psychotherapy 32.1 (2005): 47-59.

Pezdirc Bartol, Mateja. Najdeni pomeni: empirične raziskave recepcije literarnega dela. Ljubljana: Slavistično društvo Slovenije, 2010.

Reščič Rihar, Tatjana, in Jože Urbanija. Biblioterapija. Ljubljana: Znanstvena založba Filozofske fakultete, 1999.

Ross, Catherine Sheldrick, Lynne E. F. McKechnie in Paulette M. Rothbauer. Reading Matters: What the Research Reveals About Reading, Libraries, and Community. Westport, CT; London: Libraries Unlimited, 2006.

Virk, Tomo. Etični obrat v literarni vedi. Ljubljana: LUD Literatura, 2018.

Virk, Tomo. Literatura in etika. Ljubljana: LUD Literatura, 2021.

Virk, Tomo. Moderne metode literarne vede in njihove filozofsko teoretske osnove: metodologija 1. Ljubljana: Znanstvena založba Filozofske fakultete, 1999.

Zabukovec, Vlasta. »Biblioterapija v knjižnici«. Knjižnica 61.4 (2017): 23-34.

Žunkovič, Igor. "Nevroznanost in literatura«. Spremna beseda. Kako se literatura igra z možgani? Nevroznanost umetnosti in branja. Paul B. Armstrong. Prev. Igor Z̈unkovič. Ljubljana: Znanstvena založba Filozofske fakultete, 2015. 217-227.

\section{The Contribution of Literary Studies to Bibliotherapy}

Keywords: literary criticism / bibliotherapy / reading / narratology / psychonarratology / empathy

Today we are aware that reading is important and its effects on the readers have been proven by many studies on this subject. Its importance is not studied only by literary studies. It is an interesting research field for many other studies. The researchers have been studying bibliotherapy for more than a hundred years now, but we can trace its beginnings all the way to the Bible and ancient Greek philosophers. Researchers in the fields such as psychiatry, 
psychology, pedagogics and librarianship do most of the contemporary research on bibliotherapy. Since the books are the key component of the bibliotherapy process, it is unusual that we rarely find scientific research about bibliotherapy amongst the experts of literary studies. The article focuses on the role of literary studies in the process of bibliotherapy—how it can contribute to the quality of choosing a text for bibliotherapy. It investigates the strategies of studying literary texts when searching for a text that will appropriately affect the participant of bibliotherapy. Hence, in choosing an appropriate text the psychonarratological approach is crucial.

1.01 Izvirni znanstveni članek / Original scientific article

UDK 82.0:028

D0I: https://doi.org/10.3986/pkn.v44.i3.02 